\title{
JCEIB
}

Open Access; Volume 1 pp. 57-63; March2017

(C) Universiti Malaysia Pahang Publisher

DOI: https://doi.org/10.15282/JCEIB-V1-11.31/3/2017/1.1.1

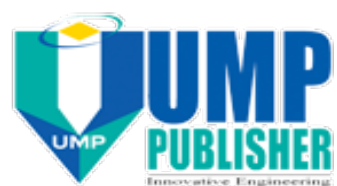

\section{COMPARISON STUDY OF ESSENTIAL OIL EXTRACTED FROM ETLINGERA ELATIOR (TORCH GINGER) BY USING SOXLET EXTRACTION}

\author{
Nur Fathin Amirah Shafie ${ }^{\mathrm{a}}$, Asdarina Yahya ${ }^{\mathrm{a}^{*}}$, Fazlena Hamzah $^{\mathrm{a}}$ \\ ${ }^{a}$ Faculty of Chemical Engineering, Universiti Teknologi MARA, 40450 Shah Alam, Selangor \\ * Corresponding author: E-mail: asda@salam.uitm.edu.my \\ Tel.: +603-55436377 Fax.: +603-55436300
}

\begin{abstract}
Significance of essential oils from Etlingera elatior (E. elatior) are growing these days and have prospective to embrace great export in future, yet the quantity of the essential oil extracted does not extant in decent rate. Therefore the purpose of this research is to determine the optimum yield of the E. elatior essential oil. The E. elatior were prepared in two conditions which are normal (fresh) and dry grinded sample. The extraction of normal and dry grinded E. elatior was conducted using Soxhlet extraction with methanol as a solvent. The extraction process was conducted at different extraction time $(2,4,6$ hours). The study indicated that the dry grinded E. elatior produced a higher yield of essential oil as compared to normal grinded E. elatior. The yield of essential oil obtained from dry grinded E. elatior was $71.44 \%$ while with normal grinded E. elatior, the yield was $56.42 \%$. The effect of extraction time towards yield of essential oil shown that prolong extraction up to 6 hours gave a higher yield of E. elatior essential oil. The constituents in the E. elatior essential oil were determined and quantified using GC-MS analysis. The analysis indicated that the E. elatior essential consist of 2-Furaldehyde, 5methyl, 3-Methyl-1,2-cyclopentanedione, Maple lactone, Furan-2,5-dial, Pyranone and 5-Hydroxymethyl furaldehyde.
\end{abstract}

Keywords: Torch Ginger, Etlingera elatior, Essential Oil, Soxhlet Extraction, GC-MS.

\subsection{INTRODUCTION}

Etlingera elatior (Zingiberaceae) or its mutual name torch ginger and widespread acknowledged in Malaysian as "bunga kantan" is symbolize as a natural to Asia and one of the most attractive of all tropical blossoming plants. There are broad traditional used of E. elatior plant in Malaysia. For example, the new shoots, flower sprouts or fruits can be consumed directly by ethnic communities or as a condiment or cooked. Jeevani (2010) stated that the flower also has been used as a lawn ornamel because the inflorescences or blossom of E. elatior are very common as a seasoning of nutrition additive and crucial elements in some traditional foods of Malaysia like asam laksa and nasi kerabu. E. elatior essential oil is extensively used as natural essences in food, scents in fragrance, and in traditional medicines (Maui, 2013). Chan (2011) reported that among 5 Etlingera species investigated, E. elatior has the highest antioxidant properties. Hazrin (2008) stated that the worldwide demands of E. elatior have opened up the worldwide opportunities due to its increasing application in pharmaceutical, aromatheraphy and also cosmetics. 
Extraction of essential oil from E. elatior can be obtained using hydro distillation or solvent extraction. However this process results in low yield, losses of its volatile compounds, residue of toxic solvent, very long extraction times and also degradation of unsaturated compound (Mostafa et al., 2013). Moreover, steam distillation always involved with a higher operating cost (Silva et al., 2013). Another recent technology in essential oil extraction is supercritical extraction. Unfortunately, supercritical $\mathrm{CO}_{2}$ method is very expensive and required a higher operating of time (Barve et al., 2010). Thus in order to overcome these limitations, optimization of the extraction process is needed to achieve higher extraction yield with minimum operation cost. It is reported by L.F $\mathrm{Hu}$ (2005), extraction is influenced by several factors including extraction time, pressure, temperature, and sample mass. Therefore, the present was focused on the optimization of the extraction process using Soxhlet extraction by varying extraction time and morphology of the raw material used in the extraction.

\subsection{METHODOLOGY}

Preparation of raw material (E. elatior infloresence)

Two different samples (normal (fresh) and dry grinded) of E. elatior were investigated. In the present study, E. elatior inflorescences were brought from the market in Shah Alam, Selangor. The inflorescences were taken from E. elatior, washed with tap water to remove dirt and stain. The broken and gloomy inflorescences were detached physically and were dried for 9 hours at $40^{\circ} \mathrm{C}$ as according to the method describle by Hazrin (2008).

\section{Extraction of essential oil}

$25 \mathrm{~g}$ of E. elatior infloresence was extracted with $200 \mathrm{~mL}$ of methanol by using Soxhlet extraction apparatus (Model: Mtop / Korea, Series Number of 2706) at 2, 4 and 6 hours of extraction time. The mixture was then evaporated in the rotary evaporator (Buchi V700 Laboratory Rotary Evaporator with Vacuum Pump) for 45 minutes. The moisture content and oil yield were calculated by using the formula in Equation 1 and 2, respectively.

$$
\begin{gathered}
\% \text { Humidity }=\frac{\text { Mass before dry -Mass after dry }}{\text { Mass after dry }} \times 100 \\
\text { Percent yield, } \%=\frac{\text { Mass of sample after extraction }(g)}{\text { Mass of sample before extraction }(g)} \times 100
\end{gathered}
$$

\section{Gas Chromatography Mass Spectrometry (GC-MS)}

The determination the concentration of chemical constituents in essential oil of E. elatior was detected using the GC-MS analyses which were performed via Varian 450 gas chromatograph with attached Varian 240 mass spectrometer. This apparatus was equipped $70 \mathrm{eV}$ with capillary column $(30 \mathrm{~m} \times 0.25 \mathrm{~mm} \times$ film thickness $0.25 \mu \mathrm{m})$ at intermediate polarity. Injector temperature was set at $250^{\circ} \mathrm{C}$ and oven temperature was programmed initially $60{ }^{\circ} \mathrm{C}$ with 2 min hold then 60 to $120{ }^{\circ} \mathrm{C}(2 \mathrm{~min}$ hold $)$ with $3^{\circ} \mathrm{C}$ $\min ^{-1}$ temperature programming and 120 to $270{ }^{\circ} \mathrm{C}$ at a rate of $2{ }^{\circ} \mathrm{C} \mathrm{min}{ }^{-1}$. Injection volume was $1 \mu \mathrm{L}$ with average velocity of $37 \mathrm{~cm} \mathrm{~s}^{-1}$. Helium was used as carrier gas and the flow rate was set at $1 \mathrm{~mL} \mathrm{~min}^{-1}$ (Faridahanim et al., 2007). 


\subsection{RESULTS AND DISCUSSION}

Extraction Yield at different E. elatior morphology

Table 1 show the moisture content of the prepared E. elatior before extraction was conducted. The purposed of the drying is to maximum the essential oil extracted from the material. The average of the moisture content for the dried sample was $7.13 \%$. The dried E. elatior used in the extraction was controlled its moisture content to the value below than $10 \%$. The yield of the essential oil at different morphology of E. elatior is shown in Figure 1.

Table 1: Moisture Content of dried E. elatior.

\begin{tabular}{cccc}
\hline Sample & Sample Mass (g) & Final Mass (g) & $\begin{array}{c}\text { Moisture Content, } \mathbf{x} \\
\mathbf{( \% )}\end{array}$ \\
\hline A & 38.5748 & 35.5375 & 8.55 \\
B & 33.8377 & 31.4399 & 7.63 \\
C & 33.4802 & 31.3310 & 6.86 \\
\hline
\end{tabular}

The results indicated that normalgrinded E. elatior gave lower yield of the E. elatior essential oil as compared to the dried grinded E. elatior. It shows that the dried grinded E. elatior gave $21-30 \%$ higher of extraction yield.

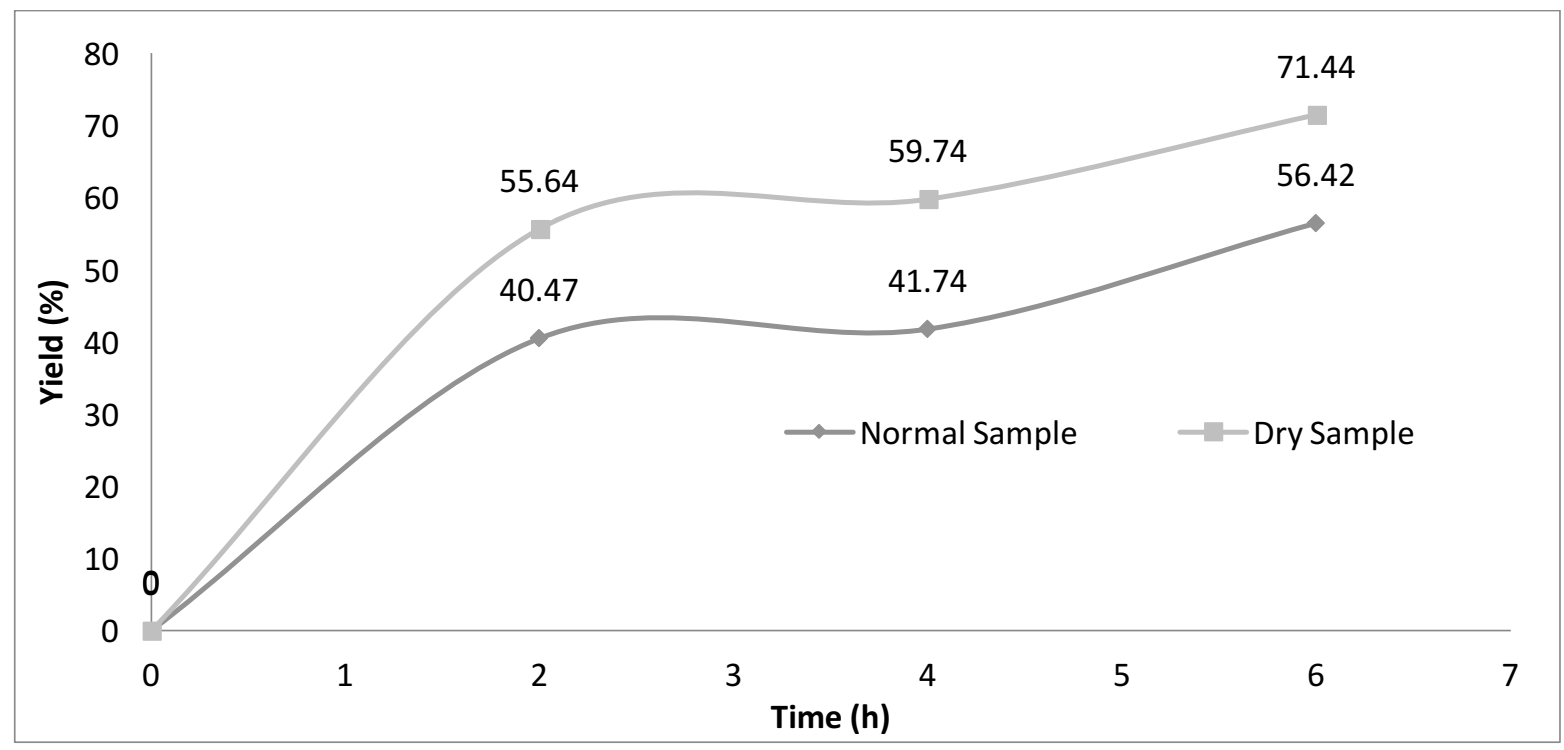

Figure 1: Percent Yield of E. elatior Essential Oil

While for the effect of extraction time on the yield of the essential oil indicated that prolong of the extraction period capable to increase the yield of the essential oil for normaland dry grinded of E. elatior. The results show that 6 hours extraction time produced the highest essential oil up to $56.42 \%$ and $71.44 \%$ oil yield for normal and dried grinded E. elatior respectively. Both samples showed an increment of essential oil yield as the extraction time increased and dry E. elatior is preferable to enhance yield of extraction. The result is in agreement with the finding by Jeevani et. al., (2011) which determine that drying might reduce the amount of oil in each plant, but can greatly increase the yield per batch. According to Bence (2008) moisture contents between 7 and $18 \%$ had little effect on extractability of oil. However, the water had a negative entrainer 
effect by extraction of samples containing more than $18 \%$ water. When the moisture content was increased, a decrease in efficiency was found. In the case of high moisture content $(\sim 85 \%)$ the extraction was almost inhibited.

\section{Chemical Constituent of E. elatior Essential Oil}

The extracted oil was analyzed for its chemical constituent via a GC-MS. Each component in the extracted oil was identified through matching with data of various components in the mass spectrometer library. The GCMS spectrum of E. elatior is shown in Figure 2 and Table 2 listed the outcome of the matching process, indicating the quality of the matching in terms of percentage, following the international standard compounds of E. elatior essential oil.

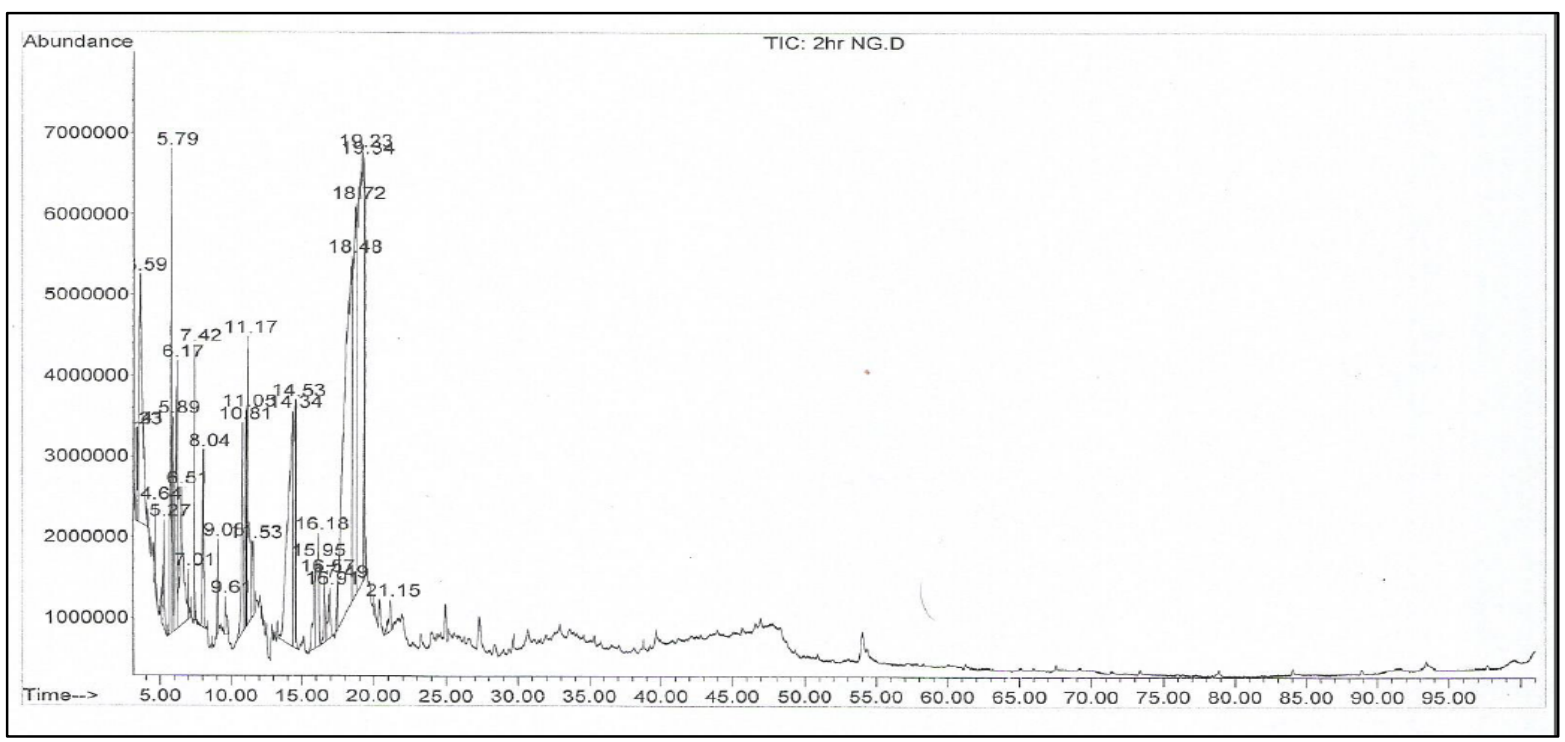

Figure 2: The Chemical constituent of the E. elatior Essential Oil for 2 Hours Extraction of Normal Sample

Table 2: Constituent of E. elatior Essential Oil Natural Samples (2 Hours Extraction)

\begin{tabular}{clcc}
\hline $\begin{array}{c}\text { RT } \\
(\mathbf{m i n})\end{array}$ & \multicolumn{1}{c}{ Component } & CAS \# & $\begin{array}{c}\text { Qual } \\
\mathbf{( \% )}\end{array}$ \\
\hline 3.23 & $\begin{array}{l}\text { (S)-[(S)-2-Phenyl-1,3,2-dioxaborolan-4-yl]-1,2- } \\
\text { ethanediol }\end{array}$ & $074807-80-0$ & 36 \\
3.41 & 2-furaldehyde & $000098-01-1$ & 35 \\
3.59 & 2-furaldehyde & $000098-01-1$ & 72 \\
4.64 & Levoglucosenone & $037112-31-5$ & 64 \\
5.26 & Butanoic acid, 2-ethyl-3-oxo-, methyl ester & $051756-08-2$ & 50 \\
5.79 & Oxime-, methoxy-phenyl & $1000222-86-$ & 90 \\
& & 6 & \\
5.89 & 2(5H)-Furanone & $000497-23-4$ & 59 \\
6.17 & 1,2-Cyclopentanedione & $003008-40-0$ & 72 \\
6.51 & 2-Furancarboxaldehyde, 5-methyl & $000620-02-0$ & 53 \\
7.01 & 2-Furancarboxaldehyde, 5-methyl & $000620-02-0$ & 72 \\
7.42 & 3,4-Diflouronisole & $115144-40-6$ & 50 \\
8.04 & 2H-Pyran-2,6(3H)-dione & $005926-95-4$ & 72 \\
\hline
\end{tabular}




\begin{tabular}{clrc}
\hline 9.08 & Maple lactone & $000080-71-7$ & 87 \\
9.61 & 1H-Indole, 1-methyl-2-phenye & $003558-24-5$ & 25 \\
10.81 & Furan-2,5-dial & $000823-82-5$ & 59 \\
11.05 & 2-Furancarboxylic acid, hydrazide & $003326-71-4$ & 46 \\
11.17 & 2,4,5-Trihydroxypyrimidine & $000496-76-4$ & 53 \\
11.53 & 1,3-Bis(trimethylsilyl)benzene & $002060-89-1$ & 72 \\
14.34 & Pyranone & $028564-83-2$ & 38 \\
14.53 & Pyranone & $028564-83-2$ & 72 \\
15.95 & 4H-Pyran-4-one, 3,5-dihydroxy-2-methyl & $001073-96-7$ & 55 \\
16.18 & N-Benzyloxylcarbonyl-1-alanyl-1-alanine ethylamide & $066382-92-1$ & 43 \\
16.57 & 1,2-Benzenediol & $000120-80-9$ & 87 \\
16.91 & 5-Acetoxymethyl-2-furaldehyde & $010551-53-3$ & 53 \\
17.49 & 5-(p-Aminopenyl)-4-(p-tolyl)-2-thiazolamine & $094460-46-5$ & 59 \\
18.48 & 2-Furancarboxaldehyde, 5-(hydroxymethyl) & $000067-47-0$ & 91 \\
18.72 & 2-Furancarboxaldehyde, 5-(hydroxymethyl) & $000067-47-0$ & 91 \\
19.23 & 2-Furancarboxaldehyde, 5-(hydroxymethyl) & $000067-47-0$ & 91 \\
\hline
\end{tabular}

Considering a minimum of $60 \%$ matches with the standard components in the library, only 7 chemicals constituent were identified from the list of chemicals constituents distinguished in all samples presents in Table 3. These components were 2-Furaldehyde, 2-Furaldehyde, 5-methyl, 3-Methyl-1,2-cyclopentanedione, Maple lactone, Furan-2,5dial, Pyranone and 5-Hydroxymethyl furaldehyde. These chemicals represent the quality of the extracted E. elatior oil, which gave essential oil characteristics.

Table 3: Major Components of All E. elatior Essential Oil Samples

\begin{tabular}{|c|c|c|c|c|c|c|c|c|}
\hline \multirow[t]{3}{*}{ Component } & \multirow{3}{*}{$\begin{array}{c}\text { CAS } \\
\text { no. }\end{array}$} & \multirow{3}{*}{$\begin{array}{c}\text { Formu } \\
\text { la }\end{array}$} & \multicolumn{6}{|c|}{ Yield (\%) } \\
\hline & & & \multicolumn{3}{|c|}{ Normal } & \multicolumn{3}{|c|}{ Dry } \\
\hline & & & $2 \mathrm{hr}$ & $4 \mathrm{hr}$ & $6 \mathrm{hr}$ & $2 \mathrm{hr}$ & $4 \mathrm{hr}$ & $6 h r$ \\
\hline 2-Furaldehyde & $\begin{array}{l}00009 \\
8-01-1\end{array}$ & $\mathrm{C}_{5} \mathrm{H}_{4} \mathrm{O}_{2}$ & 6.19 & 4.22 & 3.86 & 6.86 & 9.43 & 10.42 \\
\hline $\begin{array}{l}\text { 2-Furaldehyde, } 5 \text { - } \\
\text { methyl }\end{array}$ & $\begin{array}{l}00062 \\
0-02-0\end{array}$ & $\mathrm{C}_{6} \mathrm{H}_{6} \mathrm{O}_{2}$ & 4.72 & 3.92 & 2.22 & 4.64 & 5.53 & 5.56 \\
\hline $\begin{array}{l}\text { 3-Methyl-1,2- } \\
\text { cyclopentanedion } \\
e\end{array}$ & $\begin{array}{l}00076 \\
5-70-8\end{array}$ & $\mathrm{C}_{6} \mathrm{H}_{8} \mathrm{O}_{2}$ & 0.52 & 0.63 & 0.97 & 0.42 & 0.46 & 0.56 \\
\hline Maple lactone & $\begin{array}{l}00008 \\
0-71-7\end{array}$ & $\begin{array}{c}\mathrm{C}_{6} \mathrm{H}_{10} \mathrm{O} \\
3\end{array}$ & 0.52 & 0.63 & 0.97 & 0.42 & 0.46 & 0.56 \\
\hline Furan-2,5-dial & $\begin{array}{l}00082 \\
3-82-5\end{array}$ & $\mathrm{C}_{6} \mathrm{H}_{4} \mathrm{O}_{3}$ & 2.78 & 3.21 & 3.36 & 2.78 & 2.74 & 2.3 \\
\hline Pyranone & $\begin{array}{l}02856 \\
4-83-2\end{array}$ & $\mathrm{C}_{6} \mathrm{H}_{8} \mathrm{O}_{4}$ & 11.87 & 11.94 & 12.47 & 10.82 & 10.78 & 10.55 \\
\hline $\begin{array}{l}\text { 5-Hydroxymethyl } \\
\text { furaldehyde }\end{array}$ & $\begin{array}{l}00006 \\
7-47-0\end{array}$ & $\mathrm{C}_{6} \mathrm{H}_{6} \mathrm{O}_{3}$ & 50.41 & 49.59 & 45.67 & 52.36 & 44.65 & 39.61 \\
\hline Others & & & 22.99 & 25.86 & 30.48 & 21.7 & 25.95 & 30.44 \\
\hline \multicolumn{3}{|c|}{ Total } & 100 & 100 & 100 & 100 & 100 & 100 \\
\hline
\end{tabular}


All of the constituent present in the E. elatior has various industrial applications. For example, 5-Hydroxymethyl furaldehyde is important as flavoring representatives in foods (Li et. al., 1988) and showed the biggest peak range tailed by Pyranone, a natural ingredients and extractives. 2-Furaldehyde gave the scent of almond while 2Furaldehyde, 5-methyl are skillful of foraging peroxynitrite. 3-Methyl-1,2cyclopentanedione isused as cockroach attractant as reported by Blanco et. al,(1991). Moreover, Maple lacton isfunction as a regular constituents and extractives and 2 Furan2,5-dial is one of the flavoring agent in numerous food elements (Meidell and Filipello,1969). Besides, 5-Hydroxymethyl furaldehyde is used in the production of dialdehydes, glycols, ethers, aminoalcohols, acetals and in aqueous acid to catalyses ring opening.

\subsection{CONCLUSIONS}

The extraction of E. elatior essential oil using dissimilar conditions (dry and normal) gave significant impact on the percentage of essential oil yield. Dry grinded E. elatior produced 21-30\% higher yield as compared to normal E. elatior. While, prolong of the extraction time up to 6 hours result up to $71.4 \%$ of the essential oil yield. The chemical composition of essential oil after extracted in Soxhlet extraction method determined by GC-MS quantified 7 chemical components that exist the essential oil which are 2-Furaldehyde, 5-methyl, 3-Methyl-1,2-cyclopentanedione, Maple lactone, Furan-2,5-dial, Pyranone and 5-Hydroxymethyl furaldehyde. These chemical constituents have a great potential in various industrial application.

\section{ACKNOWLEDGEMENTS}

Deepest gratitude to Malaysia Ministry of Education and Universiti Teknologi MARA(UiTM) for the financial support for this project.

\section{REFERENCES}

Barve K. H., Laddha, K. S., \& Jayakumar, B. (2010). Extraction of saponins from Safed Musli. Pharmacognosy Journal, 2: 561-564.

Bence N., B. Simandi. 2008. Effects Of Particle Size Distribution, Moisture Content, And Initial Oil Content On The Supercritical Fluid Extraction Of Paprika. The Journal of Supercritical Fluids. Volume 46, (Issue 3): 293-298.

Blanco Gomis D., Gutiérrez Alvarez, M.D. Sopeña Naredo, L. \& Mangas Alonso, J.J.(1991) High-Performance liquid chromatographic determination of furfural and hydroxymethylfurfural in apple juices and concentrates. Chromatographia, 32:4548.

Chan E. W.C., Lim Y.Y. \& Wong S. K. (2011). Phytochemistry and Pharmacological Properties. Of Etlingera elatior: A Review, UCSI University, Faculty of Applied Sciences Kuala Lumpur, Malaysia.

Faridahanim M. J., Che P. O., \& Nor H. I., Khalijah A. (2007). Analysis of Essential Oils of Leaves, Stems, Flowers Andrhizomes of Etlingera Elatior (Jack) R. M. Smith. The Malaysian Journal of Analytical Sciences, 11(1): 269-273.

Han C. V., Bhat R. \& Rusul G. (2012). Flower Extracts and Their Essential Oils as Potential Antimicrobial Agents for Food Uses and Pharmaceutical Applications. Comprehensive Reviews in Food Science and Food Safety, 11(1): 34-55. 
Hazrin A. (2008). Monitoring of Quality of Essential Oil from Etlingera sp. 2 (Zingaberaceae) by GC and GC-MS. Universiti Malaysia Pahang: Faculty of Chemical and Natural Resources Engineering.

Jeevani M. M. O. W., Bhat R. \& Alias A. K. (2011). Effect of Extraction Solvents on the Phenolic Compounds and Antioxidant Activities of Bunga Kantan (Etlingera elatior Jack.) Inflorescence. Journal of Food Composition and Analysis, 24: 615-619.

Jeevani O. W., M. M., Karim, A. A. \& Bha R. (2010). Evaluation of nutritional quality of torch ginger (Etlingera elatior Jack.) inflorescence. International Food Research Journal, 18(4): 1415-1420.

L.F Hu, S.P.Li, H.Cao, J.J.Liu, J.L.Gao F.Q.Yang, Y.T Wang. 2005. GC-MS Fingerprint of Pogostemon Cablin in China. Institute of Chinese Medical Science, University of Macau.

Li Z-F., Sawamura, M. \& Kusunose, H. (1988) Rapid determination of furfural and 5hydroxymethylfurfural in processed citrus juices by HPLC. Agric. Biol. Chem., 52 : $2231 \neg 2234$.

Maui M. (11 April, 2013). Hawaiian Ginger:Not Just For Eating. Retrieved on 6 April, 2014, from The Private Naturalishttps://theprivatenaturalist.wordpress.com/tag/torch-ginger.

Meidell E. \& Filipello, F. (1969) Quantitative Determination of Hydroxymethylfurfural in Sherries and Grape Concentrate. Am. J. Enol. Viticult, 20(3):164-168

Mostafa A., Sudisha, J., El-Sayed, M., Ito, S. -I., Yamauchi, N., \& Shigyo, M. (2013) Aginoside saponin, a potent antifungal compound, and secondary metabolite analyses from Allium nigrum L. Phytochemistry Letters, 6: 274-280.

Silva L. P., Pereira, M. J., Azevedo, J., Gonçalves, R. F., Valentāo, P., de Pinho P. G., \& Andradea P. B. (2013) Glycine max (L.) Merr., Vigna radiate L. and Medicago sativa L. sprouts: A natural source of bioactive compounds. Food Research International, 50:167-175. 